\title{
MONUSCO: a atuação brasileira em operações de paz robustas
}

\author{
Graziene Carneiro de Souza ${ }^{1}$
}

No início de 2013, o CSONU aprovou a resolução 2098, a qual estabeleceu a criação da FIB da MONUSCO (Missão de Estabilização das Nações Unidas na República Democrática do Congo) com mandato de realizar, inclusive, operações ofensivas. Pela primeira vez na história das operações de paz sob a bandeira desta organização, permitiu-se o uso da força para neutralizar grupos armados. Neste contexto, o engajamento ativo da FIB possibilitou que os aspectos político, militar, e humanitário da MONUSCO fossem conjuntamente adaptados, influenciando a operacionalização da proteção de civis. Para comandar a força militar da missão, o CSONU nomeou o General-de-Divisão Carlos Alberto dos Santos Cruz, brasileiro, enaltecendo "questionamentos" sobre a participação do Brasil nas operações de paz sob a égide da ONU.

O investimento brasileiro nas operações de manutenção da paz daquela organização é de longa data e se intensificou nas últimas décadas. Com ComandantesGerais de Força Militar na Missão das Nações Unidas para a Estabilização no Haiti MINUSTAH, na Força Interina da ONU no Líbano - UNIFIL e na Missão de Estabilização das Nações Unidas na República Democrática do Congo - MONUSCO, o Brasil mostra sua credibilidade no contexto das operações de paz. Todavia, diante da nova discussão sobre a proteção de civis nas operações de paz robustas, ${ }^{2}$ (Braga, 2010)

\footnotetext{
${ }^{1}$ Mestre em Estudos Estratégicos de Defesa e Segurança Internacional - Universidade Federal FLuminense UFF

${ }^{2}$ Operações de paz robustas são as missões de paz que realizam operações militares ofensivas. 
implementadas nas ações militares da MONUSCO, teria o país intenção de fornecer tropas militares para exercer este tipo de mandato?

Este artigo expõe o direcionamento da política externa brasileira sobre o emprego de tropas militares em operações robustas. Não se pretende aqui aprofundar o debate sobre a participação brasileira nas operações de paz da ONU, de forma geral, menos ainda sugerir o envio de contingente a alguma operação de paz, aventa-se, sim, sobre a atuação do General-de-Divisão Carlos Alberto dos Santos Cruz na MONUSCO e a possibiliade de o Brasil exercer oficialmente mandato em operações de paz com ações ofensivas de alta intensidade.

\section{A MONUSCO e o inedistismo de sua Força da Brigada de Intervenção}

Em março de 2013, na tentativa de sublinhar as causas do conflito e garantir uma paz sustentável, tanto no país quanto na região, o CSONU exigiu a revisão estratégica da MONUSCO e adotou, unanimemente, a resolução 2098, a qual estendia o mandato da MONUSCO até 31 de março de 2014 e criava a FIB, especializada no fortalecimento desta operação. (S/2013/131.5, par. 5)

A resolução 2098 condenou fortemente o Movimento March 23 (M23), as Forças Democráticas para Libertação de Ruanda (RDLR), o Exército de Resistência do Senhor (LRA) e "todos outros grupos armados e suas contínuas violações e abusos aos direitos humanos." Inicialmente, a FIB foi autorizada sob uma base excepcional, sem criar precedente ou qualquer prejuízo que discordasse dos princípios das operações de paz da ONU. A FIB consistiria de três batalhões de infantaria, um de artilharia, uma força especial e uma companhia de reconhecimento com sede em Goma, comandada diretamente pelo Comandante da Força da MONUSCO, e teria a responsabilidade de neutralizar grupos armados e o objetivo de contribuir na redução de ameaças postas por 
estes grupos à autoridade do Estado e à segurança de civis no leste da RDC. Frente ao cenário daquela operação, atribui-se como mandato da FIB, a responsabilidade de:

realizar operações ofensivas, unilateralmente ou em conjunto com as FARDC, de forma robusta, highlymobile e versátil e em estreita conformidade com o direito internacional, incluindo o direito internacional humanitário (...) para evitar a expansão de todos os grupos armados, para neutralizá-los, e para desarmá-los (...). (S/RES/2098.28, par. 9)

A FIB é a primeira força de combate ofensiva criada para operacionalizar ações militares contra grupos armados na RDC. Alguns autores consideram que na história das operações de paz sob a égide das Nações Unidas, a presença de forças com este tipo de conformação e mandato foi utilizada nos casos da Somália e Haiti. (Blyth, 2013) Entretanto, de acordo com Priscila Fett, os dois casos "não servem de base comparativa" uma vez que ambos representam o modelo de missão de estabilização, não sendo "adequados para fazer frente aos níveis de violência encontrados no país africano". (Fett, 2013) No Departamento de Operações de Manutenção da Paz do Secretariado das Nações Unidas, o debate sobre operações robustas não é recente. Ele permeia sobre a legitimidade da ação ofensiva e o perigo do limite do uso da força exercido por operações multinacionais.

A partir de suas características, as operações de paz sob égide da ONU foram divididas em três fases. (Barnet, 1995; p. 415) O período entre 1956 e 1987 foi assinalado com o auge de operações de manutenção da paz definidas como "clássicas", "tradicionais" ou de "primeira geração," a maioria delas com mandatos que objetivavam o monitoramento de cessar-fogos, tréguas e armistícios, o patrulhamento 
de fronteiras e zonas de exclusão militar, o apoio à retirada de tropas e o acompanhamento de negociações para a assinatura de tratados de paz definitivos. (Baylis; Smith, 2006; 412) Após a Guerra Fria, as operações de manutenção da paz foram denominadas como de "segunda geração," o que de acordo com Mark Malan, significa operações de paz desenvolvidas em associação ao fim dos conflitos remanescentes da Guerra Fria, em que a ONU, ou outra organização internacional, buscava a negociação de soluções políticas baseadas no compromisso mútuo dos adversários. (Malan, 1998; p. 2)

A partir da segunda geração, a ONU passou a se envolver no término de conflitos internos, com a atribuição de tarefas multidimensionais às tropas mantenedoras da paz, que normalmente incluíam atividades sobre desarmamento, desmobilização e reintegração. No entanto, nessa mesma década, ainda em 1992, o então secretário-geral Boutros-Ghali classificou as missões aprovadas sob o Capítulo VII como a "terceira geração" (A/47/277- S/24111, 1992) das operações de paz, multilaterais e multidimensionais, ${ }^{3}$ as quais envolviam a proteção de civis e mandatos diferenciados, relacionados às características das novas guerras. Caracterizados pelas dificuldades das distinções tradicionais entre "vítima e agressor, público e privado, crime de guerra e delito, os novos conflitos deram origem a impasses relacionados aos três princípios norteadores das operações de paz; o consentimento das partes, a imparcialidade/neutralidade e o uso da força apenas em caráter excepcional." (UNDPKO, 2008; 31)

Nas últimas décadas, a "terceira geração" de operações de paz representadas pelo consenso nas Nações Unidas tornou-se a principal resposta às violações sistemáticas dos

\footnotetext{
${ }^{3}$ As Nações Unidas definem missões "multidimensionais," aquelas operações “criadas para assegurar a implementação de abrangentes acordos de paz e ajudar a estabelecer as bases para uma paz sustentável."
} 
direitos humanos e à ameaça à paz e à segurança internacionais. ${ }^{4}$ Segundo Thiago Rodrigues,

a ampliação do conceito de segurança, portanto, implicou no reconhecimento de um novo sujeito de segurança - as populações - e de um novo objeto de segurança mais variado e extenso, combinando ameaças provocadas diretamente sobre os indivíduos (por exemplo, a violência étnica ou genocídios perpetrados por um Estado) ou indiretamente (como a escassez de recursos derivada da degradação ambiental)." (Rodrigues, 2012)

O esforço político de prevenir catástrofes humanitárias, no intuito de proteger o indivíduo, dentro da recente compreensão de que o ser humano e os direitos humanos devem ser valorizados na política internacional, tornou-se compromisso no cenário mundial. (Weiss, 2004) Estas inquietações, juntamente às contribuições herdadas dos debates da década de 1990, em relação à segurança humana formulada por Bernard Kouchner, ministro de assuntos estrangeiros da França entre 2007 e 2010, e Tony Blair, primeiro-ministro britânico entre 1997 e 2007, enfatizaram este compromisso, com discussões a respeito de como e quando a comunidade internacional deveria intervir e usar a força em casos de violação sistemática dos direitos humanos. ${ }^{5} \mathrm{O}$ parágrafo quinto da Resolução 1296 de 2000 foi além, anotando que:

\footnotetext{
${ }^{4}$ Em 1994, Bouttros Bouttros-Ghali anunciou que as operações de manutenção da paz se tornariam prioridade das Nações Unidas, com aproximadamente 70.000 tropas em 17 operações em todo mundo. Em 2013, o DPKO afirmou que 117 países contribuíam com tropas, com um total de 97.157 pessoas, em 16 operações de paz. Disponível em: http://www.un.org/en/peacekeeping/resources/statistics/contributors_archive.shtml. Acesso em 05 out. 2014.

5 "Em janeiro de 2008, 119 países estavam contribuindo com forças militares e policiais para as operações de paz da ONU."
} 
"o ataque deliberado às populações civis ou outras pessoas protegidas e o cometimento de violações sistemáticas, flagrantes e generalizadas do direito internacional humanitário e de direitos humanos em situações de conflito armado podem constituir uma ameaça à paz e à segurança internacionais... prontidão a considerar tais situações e, sempre que necessário, adotar medidas adequadas." (S/RES/1296, 2000)

A implementação do conceito de segurança humana em operações de paz é vista na aplicação da proteção de civis, ainda que a definição de proteção de civis não tenha sido determinada pelo Conselho de Segurança. Contudo, em setembro de 1999, o Conselho adotou a Resolução 1265, na qual expressou a vontade da comunidade internacional em responder a situações de conflito armado, onde civis são alvos ou a assistência humanitária está sendo obstruída deliberadamente, a considerar a adotar medidas apropriadas. ${ }^{6}$ A Resolução, igualmente, alertou os Estados a ratificarem ameaças aos direitos humanos e processarem aqueles responsáveis por genocídio, crimes contra a humanidade e sérias violações a lei humanitária internacional.

Apesar da compreensão do conceito de proteção de civis permanecer a mesma, no caso da MONUSCO, a criação da FIB e a autorização do uso da força deram início, defendemos aqui, a uma nova conduta na proteção da violência física. ${ }^{7}$

\footnotetext{
${ }^{6}$ Maiores descrições sobre a emergência do conceito da Proteção de Civis no Conselho de Segurança está disponível no Relatório do Conselho de Segurança intitulado "Protection of Civilians," N. 2, 14 de out. de 2008.

${ }^{7}$ Conceito de "Ilhas de Estabiliade." Ver Statement of SRSG Martin Kobler to the Security Council. Building on the Momentum. 14 mar. 2014. Disponível em:

http://monusco.unmissions.org/Portals/monuc/Speeches/140314\%20Statement\%20of\%20SRSG\%20Martin\%20Koble r\%20to\%20the\%20Security\%20Council\%20-\%20March\%202014\%20(\%20version\%20\%20W\%20Eng).pdf. Acesso em 10 set. 2014.
} 
Ao longo do processo de evolução das operações de paz, seus três princípios norteadores (consenso, imparcialidade e uso mínimo da força) foram adaptados às necessidades de respostas imediatas às novas ameaças e conflitos. Neste contexto, atuações da ONU como no caso do Haiti (1990-1997), da Somália (1992-1995), da exIugoslávia (1992-1995), de Ruanda (1993-1996) e de Serra Leoa (1998-2005), apesar de planejadas para responder a distintos contextos locais, são exemplos de missões que inicialmente possuíam um mandato multidimensional não coercitivo, e que, com a escalada da violência, incorporaram elementos impositivos para tentar superar a fragilidade de situações de recrudescimento de agressões, crimes contra a humanidade e abuso dos direitos humanos.

O caso da MONUSCO representa uma recente inovação no tange os três princípios. A resposta inédita do CSONU, em 2013, por meio da Resolução 2098, que estabeleceu a criação da FIB da MONUSCO com mandato para realizar, inclusive, operações ofensivas, é um novo método na operacionalização da proteção de civis.

De acordo com a Capstone Doctrine 8 das Nações Unidas, as operações de paz são desdobradas com o consentimento das principais Partes do conflito. (UNDPKO, 2008; p.31) Na República Democrática do Congo, a MONUSCO obteve consentimento do Governo congolês, a outra parte do conflito, a saber, os grupos armados ilegais, foram considerados a principal ameaça à segurança da população. Neste contexto, não se fazia conveniente buscar consentimento uma vez que aqueles grupos armados ilegais eram a parte "inimiga." Elucidado naquele mesmo documento, a imparcialidade significa que o mandato deve ser implementado sem favorecer ou prejudicar qualquer das partes. (UNDPKO, 2008; 33) Na MONUSCO, o princípio da imparcialidade/neutralidade foi

\footnotetext{
8 A Capstone Doctrine é um documento do Departamento de Operações de Paz da ONU, produzido em 2008 , que contém os princípios e as linhas gerais sobre as operações de paz da ONU. Disponível em: http://pbpu.unlb.org/pbps/library/capstone_doctrine_eng.pdf Acesso em 26 jul. 2014.
} 
esvaziado quando se identificou as Partes do conflito e se decidiu "autorizar a FIB a usar todos os meios necessários para alcançar e operacionalizar seu mandato," apoiando a soberania do Estado e o Governo da RDC nos esforços de estabilização e consolidação da paz.

A criação da FBI toca diretamente no princípio mais controverso das operações de paz, o uso da força. Na RDC, o uso da força em ações ofensivas unilaterais ou em conjunto com as FARDC, de modo robusto e versátil para neutralizar grupos armados ocasiona mudanças na compreensão destes três pilares. O princípio do não-uso da força, exceto em autodefesa, data do primeiro desdobramento de capacetes azuis armados da ONU, em 1956. Entretanto, ao longo da evolução das operações de paz, as operações de manutenção de paz, passaram a empregar, pontualmente, o uso da força, como no Congo, entre 1960 e 1964, na Bósnia-Herzegovina, no período de 1992 a 1995, na Somália entre 1993 e 1995, e recentemente, no Haiti entre 2004 e 2006. Apesar de seguirem o modelo de missão de estabilização, e não possuírem os mesmos níveis de violência encontrados na RDC, o CSONU permitiu o uso da força limitado naquelas operações, em consonância com o princípio da autodefesa.

Na RDC, o CSONU percebeu a dificuldade de seu componente militar em antecipar-se às ameaças e agir pró-ativamente a fim de reduzir vulnerabilidades e dissuadir os grupos armados. Destarte, mais uma vez, a necessidade de atualização, adaptação e evolução para realizar a proteção efetiva de civis foi concretizada na FIB. Constituída de 3.069 militares da África do Sul, Maláui e Tanzânia, o mandato da FIB modificou a implementação da proteção de civis. Se anteriormente, os capacetes azuis assistiam estáticos aos abusos dos direitos humanos, à violência sexual e aos crimes contra a humanidade, na RDC, a FIB passou a desempenhar ações preemptivas com o propósito de evitar tais violações. As ações ofensivas preemptivas embasadas em dados 
da inteligência e de recursos tecnológicos, usados pela primeira vez em operações de paz, como os drones, permitiram resultados positivos na proteção de civis.

A proteção de civis está relacionada à proteção física do civil, e na RDC ela é implementada por meio de ações robustas da FIB e não somente pela presença dos capacetes azuis. O General-de-Divisão Carlos Alberto dos Santos Cruz enfatizou que a melhor proteção de civis, no que tange a proteção física, está relacionada à identificação da ameaça, sua eliminação ou neutralização.

“É preciso uma postura ativa. A presença pode causar dissuasão, mas sozinha, ela não é efetiva. É preciso ter presença e dinâmica de ação. A nossa visão na MONUSCO é a proteção de civis através da ação, não só da presença. A presença segue o modelo tradicional, e neste caso, o contingente militar é passivo, só reagindo e não se antecipando. Isso não é o ideal. Longo tempo sem agir, em primeiro lugar, faz com que a presença deixe de ser dissuasória, por que não se acredita que a missão vá agir. E segundo, é um processo de desmoralização. $\mathrm{O}$ contingente militar dissuade o agressor quando ele acredita que a missão agirá se ele tentar fazer algo. Nós queremos uma missão que se antecipe e tenha uma dinâmica de ação antes que o problema aconteça." 9

O fato de ser um General brasileiro, o líder desta missão que operacionaliza o novo modelo da proteção de civis em ações ofensivas, na RDC, remete às questões sobre a posição da chancelaria brasileira ao ineditismo da FIB.

\footnotetext{
${ }^{9}$ Entrevista conduzida com o Comandante da Força Militar da MONUSCO, General-de-Divisão Carlos Alberto dos Santos Cruz, no dia 4 de setembro de 2014, em Goma, North Kivo, DRC.
} 


\section{Política externa do Brasil: o General na MONUSCO e a contribuição de tropas para missões robustas}

A inovação da criação da FIB sob comando direto do Comandante da Força frisou-se como excepcional, e a nomeação de um General brasileiro para este cargo foi se não inusitada, no mínimo interessante. ${ }^{10}$ Santos Cruz foi escolhido, especificamente, por Ban Ki-moon para atuar como funcionário da ONU. Claramente, havia a necessidade de apoio do governo brasileiro. Na época de sua indicação, o General havia ido para a reserva, já em 1 de dezembro de 2012, e trabalhava como Assessor na Secretaria de Assuntos Estratégicos da Presidência da República (SAE/PR). A fim de atender ao pedido do secretário-geral, Santos Cruz voltou à ativa para liderar a força millitar da MONUSCO. De certa forma, foi um caso pontual e não deixou de causar certo constrangimento para alguns setores das Forças Armadas e para a política externa brasileira.

A indicação do General significou a tentativa de Ban Ki-moon em superar os desafios de desmoralizacão da ONU na RDC. O General-de-Divisão Carlos Alberto dos Santos Cruz foi Comandante-Geral da missão no Haiti, entre setembro de 2006 e abril de 2009, e naquela ocasião, obteve resultados positivos e sucesso nas avaliações de implementação das operações militares. ${ }^{11}$ A MINUSTAH implementou, igualmente, ações ofensivas, apesar de não estarem previstas em seu mandato. Contudo, elas não tiveram o mesmo nível de violência que na DRC. (Dziedzic, Perito, 2008)

\footnotetext{
10 A última vez que um General brasileiro comandou forças militares de agressão foi na campanha da Força Expedicionária Brasileira na Itália durante a Segunda Guerra Mundial.

${ }^{11}$ Disponível em: http://www.un.org/en/peacekeeping/missions/minustah/reports.shtml. Acesso em 18 de julho de 2014.
}

RRASILIANA- Journal for Brazilian Studies. Vol. 3, n.2 (March, 2015). ISSN 2245-4373. @) (ब) ब( 
Neste país, relatórios do Secretário-Geral revelaram a fragilidade do sistema de coleta e análise de informações da MONUSCO, bem como a dificuldade de seu componente militar em antecipar-se às ameaças e agir pró-ativamente para reduzir vulnerabilidades e dissuadir opositores. Percebeu-se, assim, a necessidade de atualização, adaptação e evolução para realizar a proteção de civis que tornaram-se cada vez mais complexas frente às deficiências de aportes tecnológicos e de inteligência.

Santos Cruz assumiu a missão no momento em que a mesma passava por significativa fragilidade militar e política, com o objetivo de expulsar o M23 de Goma, retomar a cidade e reconquistar a confiança da população congolesa e da comunidade internacional na ONU. Posteriormente, o sucesso das execuções das ações militares com a neutralização dos principais grupos armados e a maior garantia da proteção de civis na região de conflito, fez com que o mandato da MONUSCO e sua Brigada de Intervenção, finalizados em 28 de março de 2014, fossem renovados pelo CSONU e estendidos até 31 de março de 2015, por meio de sua resolução 2147.

Apesar de não operar na MONUSCO como oficial representante do Brasil, mas como funcionário das Nações Unidas, há certa complexidade em dissociar a imagem do General brasileiro à do Brasil. O reconhecimento de seu trabalho na MINUSTAH e a repercussão positiva de seu comando na MONUSCO tem emergido distintas proposições em relação ao interesse e à participação do Brasil nas operações de paz da ONU, principalmente, se considerado a vindoura retirada de tropas do Haiti.

É verdade que se pode verificar uma distinta atuação da política externa brasileira no início do século, com envolvimento mais pró-ativo do país nas discussões sobre a implementação das missões de paz e a sua contribuição de tropas. Ela foi enfatizada em fevereiro de 2011, quando o Brasil assumiu o comando da Força-Tarefa Marítima (MTF, na sigla em inglês) da Força Interina das Nações Unidas no Líbano (UNIFIL), quando pela primeira vez o Comando da MTF passou a cargo de país não- 
membro da OTAN (Organização do Tratato do Atlânticco Norte). Atualmente, o Brasil dispõe de militares e policiais presentes no Líbano, no Haiti, no Timor Leste, no Equador, no Peru, na Colômbia, no Saara Ocidental, na Costa do Marfim, na Libéria, e no Chipre, com um total de 1685 militares e policiais. ${ }^{12}$

Segundo o então Ministro da Defesa, Celso Amorim, a participação do Brasil na Força Interina da ONU é parte da política externa brasileira de contribuir para a solução de conflitos internacionais. Amorim afirmou, em 2014, que "não nos oferecemos, fomos chamados pelo próprio governo do Líbano e pela ONU para ajudar. Isso é uma demonstração do novo contexto em que o Brasil está inserido." 13 De acordo com Eduardo Uziel, os interesses brasileiros sobre o assunto estão nos aspectos "de caráter bilateral ou regional, embora não seja comum especificar como a participação nas missões se refletirá na prática em maior interação bilateral ou regional nem se ela ocorrerá na forma de comércio ou cooperação prestada pelo Brasil”. (Uziel, 2010)

O maior protagonismo do Brasil sobre o tema também foi visto na abertura da $66^{\underline{a}}$ Assembléia Geral das Nações Unidas, em setembro de 2011, quando a presidente Dilma Rousseff pronunciou a preocupação brasileira relacionada à implementação da intervenção militar, posteriormente, ratificada pelo documento "Responsabilidade ao Proteger: Elementos para o Desenvolvimento e Promoção de um Conceito." 14 O documento brasileiro expressou a cautela do país de recorrer a organismos regionais e sub-regionais para compor operações de manutenção da paz, uma vez que a missão

${ }^{12}$ Disponível em: http://www.un.org/en/peacekeeping/operations/global_contribution.shtml. Acesso em 18 de julho de 2014.

${ }^{13}$ Disponível em: http://www.senado.gov.br/noticias/Jornal/emdiscussao/defesa-nacional/estrategia-nacional-parareorganizaao-e-reaparelhamento-da-defesa/forca-interina-da-onu-no-libano.aspx. Acesso em 10 de julho de 2014.

$14 \mathrm{O}$ documento apresentava mais em detalhes as contestações brasileiras sobre a operação na Líbia, antes apresentadas por Dilma Rousseff discutiu as responsabilidades da comunidade internacional e principalmente do Conselho de Segurança durante a implementação da Responsabilidade de Proteger no que tange o uso da força como último recurso, a proporcionalidade dos meios usados, e as consequências do uso da força. 
poderia ser mais facilmente desvirtuada em benefício dos interesses de alguma potência ou de países vizinhos. (De Souza, 2012; 129)

Apesar disso, o Brasil reconheceu que a ONU não dispõe de recursos humanos, materiais e meios logísticos, nem de unidade de comando necessários para intervir adequadamente em conflitos que exijam ação militar propriamente dita, ou seja, ação de imposição (peace enforcement). Portanto, nesses casos, o país acredita ser inevitável a intervenção de uma aliança militar ou coalizão ad hoc, sob a liderança de um país ou países, para impor a paz e restaurar a segurança. O Brasil tem sustentado que essas alianças ou coalizões, sempre que autorizadas pelo CSONU, devem atuar com base em mandatos claros e realistas e observar estritamente o princípio da responsabilidade (accountability) perante o CSONU.

A chancelaria brasileira acredita que as operações de manutenção da paz são um instrumento útil para ajudar na solução pacífica de controvérsias, podendo auxiliar a promover negociações político-diplomáticas. Entretanto, é necessário reconhecer que nos casos, de falência estatal as partes não podem ser claramente identificadas para darem seu consentimento. ${ }^{15}$ Por isso, enfatiza a necessidade de clareza e realismo dos mandatos aprovados pelo Conselho de Segurança, salientando, igualmente, que o sucesso das operações de manutenção da paz depende da disponibilidade de recursos adequados. Em relação à questão do financiamento das operações de manutenção da paz da ONU, o Brasil considera que essas operações, enquanto despesas da organização devem ser financiadas por contribuições obrigatórias dos Estados membros, com base no artigo 17,§2 da Carta da ONU. O país tem defendido a manutenção da atual escala especial de contribuições para o financiamento das operações de paz e sublinhado que o

\footnotetext{
${ }^{15}$ Disponível em http://www2.planalto.gov.br/imprensa/noticias-de-governo/brasil-defende-na-onu-busca-de-meiospacificos-para-conter-violencia-no-mundo-e-faz-apelo-pela-responsabilidade-ao-proteger. Acesso em 15 de Março de 2012 .
}

RRASILIANA- Journal for Brazilian Studies. Vol. 3, n.2 (March, 2015). ISSN 2245-4373. @) (ब) ब( 
eventual desequilíbrio na distribuição dos países pelas quatro categorias que compõem a escala especial deve ser ajustado, caso a caso, após análise dos pedidos, à luz da situação econômica de cada solicitante. (Fontoura, 1999; 277)

Os documentos basilares sobre a política de defesa brasileiros, a Política Nacional de Defesa, a Estratégia Nacional de Defesa e o Livro Branco de Defesa corroboram os eixos estratégicos sobre o envolvimento do país nas missões de paz da ONU, bem como evidenciam a aproximação com a África. A Política Nacional de Defesa afirma o compromisso do Brasil com a defesa da paz, devendo o país "aperfeiçoar o preparo das Forças Armadas para desempenhar responsabilidades crescentes em ações humanitárias e em missões de paz sob a égide de organismos internacionais, de acordo com os interesses nacionais." (Ministério Da Defesa, 2012; Par. 7.13 e 7.14)

Na Estratégia Nacional de Defesa, o preparo das Forças Armadas é citado, relacionado diretamente às operações internacionais de apoio à política exterior do Brasil. (Ministério Da Defesa, 2012; Par. 19) No Livro Branco de Defesa, o interesse do país é marcado pela afirmação do envio de mais de 30 mil militares e policiais às operações de paz da ONU. (Ministério Da Defesa, 2012; p. 160)

De fato, desde 1956, o Brasil tem participado de 47 missões de paz das Nações Unidas. ${ }^{16}$ Segundo Paulo Roberto Campos Tarrisse da Fontoura, a participação brasileira nestas operações pode ser dividida em dois grandes episódios: ${ }^{17}$ “o período de 1957 a 1967, caracterizado pela participação em seis operações, das quais se destaca a contribuição para a UNEF I, no Sinai e na Faixa de Gaza; e o período de 1989 até 1999,

\footnotetext{
${ }^{16}$ Disponível em: http://www.senado.gov.br/noticias/Jornal/emdiscussao/defesa-nacional/estrategia-nacional-parareorganizaao-e-reaparelhamento-da-defesa/forca-militar-do-brasil-em-missoes-de-paz.aspx. Acesso em 24 de junho de 2013.

${ }^{17}$ Vale ressaltar que em cada um desses grandes momentos, o Brasil também participou de operações de manutenção da paz fora do âmbito das Nações Unidas.
} 
com participação mais variada, da qual se realça a contribuição para a UNAVEM III, em Angola." (Fontoura, 1999)

Mais de quinze anos após a pesquisa de Fontoura, publicada em 1999, podemos adicionar uma nova fase para a participação brasileira nas operações de paz da ONU, iniciada em 2004, com o envio de tropas para a MINUSTAH. Esta operação representa a missão de paz em que foi disponibilizado, o maior contingente brasileiro para o exterior com o objetivo de agir em nome da segurança coletiva. Atualmente, o país mantém aproximadamente 1375 militares e policiais naquela missão. ${ }^{18}$

A participação de tropas brasileiras, especialmente na MINUSTAH e na UNIFIL, consolidou o perfil brasileiro de contribuinte para missões de paz da ONU e promotor do desenvolvimento e, contribuiu para o aperfeiçoamento do treinamento das Forças Armadas brasileiras em áreas como segurança, engenharia, assistência humanitária e proteção civil em situações de risco e de desastres. (Donald, 2011; 536) Para o Coronel do Exército José Ricardo Vendramini, Comandante do Centro Conjunto de Operações de Paz do Brasil, ${ }^{19}$ o treinamento vem sendo muito útil para que, no seu retorno ao país, as tropas brasileiras possam incorporar a experiência adquirida no Haiti em seu trabalho no território nacional. ${ }^{20}$

Dentre as diversas motivações que levaram as tropas brasileiras ao Haiti, uma delas diz respeito à posição do Brasil dentre os tomadores de decisão no arranjo geopolítico mundial. Adicionalmente, o desejo por um assento permanente no Conselho de Segurança da ONU é um sonho antigo do país, que remonta à era Vargas. A presença

\footnotetext{
${ }^{18}$ Disponível em: www.un.org/en/peacekeeping/contributors/2014/jun14_3.pdf. Aceso em 18 de julho de 2014.

${ }^{19}$ Entrevista realizada no dia 11 de abril de 2014 com Fernando Sena, chefe da Divisão de Paz do Ministério das Relações Exteriores em Brasília, DF.

${ }^{20}$ Disponível em http://diplomaciapublica.itamaraty.gov.br/82-o-brasil-e-os-dez-anos-da-minustah. Acesso em 20 de juho de 2014.
}

RRASILIANA- Journal for Brazilian Studies. Vol. 3, n.2 (March, 2015). ISSN 2245-4373. @) (ब) ब( 
no Haiti reforçou a imagem do país como ator importante na ONU e serviu como argumento para o país pleitear uma cadeira fixa no CSONU, ainda que sua tentativa não tenha sido suficiente. De acordo com Suzeley Kalil Mathias, integrante do Grupo de Estudos de Defesa e Segurança Internacional da Universidade Estadual Paulista (Unesp), “chefiar a missão militar é uma forma de o país dizer que merece ser tratado como uma liderança, apesar das resistências regionais, e que tem condições morais e até econômicas de ser liderança". (Gombata, 2014)

Os desdobramentos dos dez anos da missão no Haiti servem como um grande laboratório para o Brasil. Segundo Rafael Villa, pesquisador de temas ligados a defesa, segurança e América Latina na Universidade de São Paulo (USP), “a MINUSTAH apresentou para a política de defesa e para as Forças Armadas a possibilidade de treinamento e maior expertise internacional. Com a missão, o Brasil ganhou reputação internacional nessa parte militar. E o resultado disso foi a escolha do General Santos Cruz para comandar a missão de paz no Congo," destacando que este "é um grande ganho político" para o país. (Gombata, 2014)

A MINUSTAH e a MONUSCO são operações de paz localizadas em regiões de relevância para o Brasil. A MINUSTAH significou uma oportunidade de o país mostrar sua capacidade de liderança regional. A MONUSCO está posicionada em um continente onde o Brasil apresenta interesse crescente sobre a aproximação do Atlântico sul.

A política externa brasileira no continente africano passou a ser enfatizada no início do governo Lula e foi conceituada por alguns autores como "autonomia pela diversificação." ${ }^{21}$ (Vigevani; Cepaluni, 2007) A priorização das relações sul-sul e o conceito de "não indiferença," na política internacional, fizeram com que o Brasil se

\footnotetext{
21 A diplomacia de Lula da Silva pode ser interpretada segundo o conceito de "autonomia pela diversificação", caracterizado pela adesão do país aos princípios e às normas internacionais por meio de alianças Sul-Sul, inclusive regionais, e de acordos com parceiros não tradicionais (China, Ásia-Pacífico, África, Europa Oriental, Oriente Médio etc.).
} 
aproximasse de países da África, principalmente, aqueles de língua portuguesa. A política africanista, uma ação estratégica do governo, visava ampliar a inserção internacional do país e seu poder de influência no continente. Em parceria com as nações africanas, o Brasil vem promovendo esforços relacionados a diversos âmbitos, na tentativa de reduzir assimetrias, acessar novos mercados e desempenhar maior protagonismo no cenário internacional. No que tange aos temas de paz e segurança, acordos de cooperação na área de defesa foram firmados com sete países africanos. ${ }^{22}$

Em relação à República Democrática do Congo, em 2010, um Memorando de Entendimento foi firmado entre o então Ministro das Relações Exteriores, Celso Amorim e o Ministro dos Negócios Estrangeiros, Alexis Thambwe-Mwamba. ${ }^{23}$ A República Democrática do Congo, também, é Estado parte da Zona de Paz e Cooperação do Atlântico Sul - ZOPACAS, por isso, é incontestável o interesse brasileiro sobre esta região da África. Em janeiro de 2013, o então Ministro Antônio de Aguiar Patriota salientou durante a II Reunião Ministerial da ZOPACAS, em Montevidéu, que a “inserção da ZOPACAS no âmbito da ONU evidencia o alcance universal dos princípios e valores que orientam a cooperação e o diálogo sul-atlântico." 24

O Brasil tem hoje três Comandantes de Força (Force-Comanders) chefiando missões de paz da ONU: o General-de-divisão Carlos Alberto dos Santos Cruz liderando

\footnotetext{
${ }^{22}$ No governo Lula, foi relançada a ZOPACAS, um foro multilateral que fomenta vários processos de integração econômica no Atlântico Sul, a exemplo da cooperação entre Mercosul, SADC e ECOWAS. WINTER, Marcella de Carvalho. A Política Africanista do Governo Lula da Silva (2003 - 2010) Disponível em: http://www.getempo.org/index.php/revistas/56-n-11-marco-de-2013/artigos/161-5-a-politica-africanista-dogoverno-lula-da-silva-2003-2010. Acesso em 23 de junho de 2014.

23 Disponível em: http://www.itamaraty.gov.br/sala-de-imprensa/notas-a-imprensa/comunicado-conjunto-entre-arepublica-democratica-do-congo-e-a-republica-federativa-do-brasil-relativo-a-visita-de-trabalho-a-republicademocratica-do-congo-do-ministro-das-relacoes-exteriores-do-brasil. Acesso em 15 de julho de 2014.

${ }^{24}$ Disponível em: $\quad$ http://www.itamaraty.gov.br/sala-de-imprensa/discursos-artigos-entrevistas-e-outrascomunicacoes/ministro-estado-relacoes-exteriores/vii-reuniao-ministerial-da-zona-de-paz-e-cooperacao-doatlantico-sul-zopacas-texto-base-do-discurso-do-ministro-antonio-de-aguiar-patriota-montevideu-15-de-janeiro-de2013. Acesso em 16 de julho de 2014.
} 
a Brigada de Intervenção da MONUSCO, na República Democrática do Congo, o Contra-almirante Flávio Macedo Brasil conduzindo a Força-Tarefa Marítima da UNIFIL, no Líbano, e o General-de-divisão José Luiz Jaborandy Júnior à frente da Força de Paz da MINUSTAH, no Haiti. De fato, isto expressa a credibilidade da diplomacia brasileira e a confiança no preparo de seus militares por parte da ONU. Em entrevista, o Generalde-divisão Carlos Alberto dos Santos Cruz afirmou que "ninguém escolhe um Comandante para liderar contingente de tamanha expressão como a da MONUSCO, militar de uma força armada que não tenha expressão." 25

Sabe-se que a capacidade militar é um dos pontos excludentes na contribuição de tropas para as operações de paz da ONU. As tropas precisam estar treinadas e qualificadas para exercer o papel de capacetes azuis. No caso da MINUSTAH, a capacidade militar brasileira foi comprovada em um cenário específico em que ações ofensivas foram implementadas em operações singulares, para desmobilização de grupos armados. Do mesmo modo, o Brasil participou em operação robusta para proteger civis, autorizada pelo Conselho de Segurança, no caso do Timor Leste, em 2013. Em 1996, durante o Governo Fernando Henrique Cardoso, o Brasil foi consultado sobre a possibilidade de incorporar militares combatentes à Força Multinacional para o Zaire (hoje, República Democrática do Congo) para socorrer refugiados e deslocados internos em meio a guerra civil. Na ocasião, a Forças Armadas e o Itamaraty estudaram opções de engajamento, mas a Força acabou não sendo mobilizada devido à superação da situação de emergência pelo próprio país. Posteriormente, em 2013, o Brasil foi consultado pelo Secretário-Geral da ONU, Ban Ki-moon, novamente, sobre a possibilidade de envio de tropas militares à MONUSCO, mas o pedido foi negado. Este período foi anterior a criação da FIB. A MONUSCO ainda não possuia o mandato

\footnotetext{
${ }^{25}$ Entrevista realizada pela autora, no dia 27 de maio de 2014, com o General-de-divisão do Exército Carlos Alberto de Santos Cruz, em Brasília, DF.
} 
vigente com operações ofensivas e, mesmo assim, a solicitação de envio de tropas foi negado pelo governo brasileiro.

“A decisão de enviar tropas militares ao exterior é uma decisão de política externa e um compromisso com a segurança do país anfitrião," salientou, em entrevista, Fernando Sena, então chefe da Divisão de Paz do Ministério das Relações Exteriores. ${ }^{26}$ Não obstante, a contribuição de tropas às operações de paz das Nações Unidas também leva em consideração alguns aspectos relevantes evidenciados, principalmente, no C34 (Comitê Especial das Nações Unidas sobre Operações de Manutenção da Paz). Neste Comitê, as principais discussões sobre os Países Contribuintes de Tropas - TCC (Troop Contribute Countries) em relação à mobilização de Forças Multinacionais salienta que "o país interessado deve oferecer meios compatíveis com as necessidades operacionais dessa força, que são definidas por um comando unificado composto pelos países participantes," afirma Fontoura. (Fontoura, 1999; 221)

Muitas variáveis são levadas em conta quando considerado os países fornecedores, tais como:

a disponibilidade de meios de alta tecnologia (logística e comunicações), a capacidade de fornecer unidades especializadas onerosas (transporte e saúde), a possibilidade de pronto emprego do contingente oferecido (algo influenciado pela localização geográfica do país fornecedor e pela sua capacidade desmobilização de efetivos) e a existência de exigências legais (consulta prévia ao Congresso). (Fontoura, 1999; 221)

\footnotetext{
26 Conjuntamente, o Itamaraty assessora o Presidente da República em relação à escolha dos cenários de participação e faz a interface necessária com as Nações Unidas e o Ministério da Defesa e aborda a instrumentalização dos engajamentos de militares brasileiros nas missões de paz. Entrevista realizada pela autora, no dia 11 de abril de 2014, com Fernando Sena, chefe da Divisão de Paz do Ministério das Relações Exteriores, em Brasília, DF.
} 
No Brasil, este debate foi alimentado pelo próprio aumento dos pedidos feitos pelo Secretariado das Nações Unidas, que gerou a necessidade de instituir um sistema de mobilização de quadros envolvendo os Três Poderes e os Estados brasileiros, bem como de aumentar o engajamento do Itamaraty nos diferentes Comitês da ONU que tratam do assunto.

A preocupação dos responsáveis pelo envolvimento brasileiro abordava o aperfeiçoamento, a seleção e o preparo dos voluntários a serem cedidos pelos Estados, de modo a evitar a sua repatriação por falta de qualificação ou por conduta profissional inadequada. Neste sentido, o Exército brasileiro, o mais expressivo tributário no âmbito da Forças Armadas brasileiras para este tipo de missão, criou, por meio de Portaria do Comandante do Exército, em fevereiro de 2005, o Centro de Instrução de Operações de Paz - CI Op Paz.

A partir da criação do CI Op Paz, os contingentes passaram a preparar-se e a serem empregados sob a luz do Cap. 7 da Carta da ONU, produzindo significativas modificações no comportamento das tropas no terreno. Em junho de 2010, a portaria no 952 do Ministério da Defesa, de mesma data, designou o Centro de Instrução de Operações de Paz (CIOpPaz), do Exército Brasileiro para a preparação de militares e civis brasileiros e de nações amigas a serem enviados em missões de paz e alterou a sua denominação, para Centro Conjunto de Operações de Paz do Brasil (CCOPAB).

Atualmente, o CCOPAB é reconhecido internacionalmente no preparo de militares para a ONU. A instituição possui intercâmbio de estrangeiros de diversas regiões do mundo e fornece cursos em Logística e Reembolso de Operações de Paz, Preparação para Missões de Paz, Coordenação Civil-Militar, Desminagem Humanitária, Preparatório para Comandantes de Sub Unidade e Pelotão, Preparação para 
Comandantes de OM e Estado Maior, Exercício Avançado de Operações de Paz e Preparação para Jornalistas em Áreas de Conflito. ${ }^{27}$

$\mathrm{O}$ adestramento de militares brasileiros para atuação na MINUSTAH possibilitou ao país reconhecimento positivo em relação às ações táticas de combate e de pacificação. O uso adequado da força pelas tropas brasileiras resultou em operações militares bem sucedidas e angariou credibilidade e legitimidade ao Brasil. Entretanto, a realidade das operações de paz robustas, exemplificadas no caso da MONUSCO, demanda distinta qualificação para o emprego de inteligência, mobilidade, comunicações e informações públicas. Neste sentido, o desenvolvimento da capacidade nacional específica para tropas e para pessoal deveria estar alinhado ao conceito e proposições deste tipo de operação de paz.

O Coronel José Ricardo Vendramini, afirmou em entrevista que "do ponto de vista militar, o Brasil é capaz de fornecer tropa para as operações de paz robustas," sublinhando que a tarefa deste tipo de missão, se baseada no mandato da FIB, de "capturar, neutralizar e desarmar os grupos armados," teria treinamento similar ao combate convencional. O Coronel Vendramini enfatizou, ainda, que o treinamento para as missões robustas deveria focar na capacitação para realizar cerco, fazer patrulhas intensivas, e reagir rapidamente a atentados, acrescentando a necessidade de equipamentos modernos com sistema de comando e controle, processamento de coleta de informações e inteligência. ${ }^{28}$

Os desafios em treinar adequadamente indivíduos e unidades para desdobramento em operações de paz da ONU, principalmente, no caso do papel da FIB,

\footnotetext{
${ }^{27}$ Disponíel em: http://www.ccopab.eb.mil.br/index.php/pt/ensino/cursos-e-estagios. Acesso em 17 de julho de 2014.

${ }^{28}$ Entrevista realizada com o Coronel de Exército, José Ricardo Vendramini, Comandante do Centro Conjunto de Operações de Paz do Brasil - CCOPAB, no dia 7 de março de 2014.
} 
é atual e evidente. Na Reunião Anual da Associação Internacional de Centros de Treinamento de Operações de Paz (IAPTC, na sigla em inglês) de 2014, na Indonésia, o tema central foi relativo a uma nova arquitetura global de treinamento para o DPKO. Esta nova arquitetura buscaria racionalizar o emprego de meios e recursos para alavancar a eficiência do treinamento e seria baseada em um projeto do Serviço de Treinamento Integrado (ITS) do DPKO com exaustiva consulta aos Estados membros, missões de campo e o Secretariado da ONU, concentrando-se no status dos materiais de treinamento existentes, nas metodologias utilizadas para treinar militares, policiais e civis e no uso das novas tecnologias para o ensino à distância..$^{29}$

A discussão sobre a capacitação de tropas militares para contribuição em operações de paz vai além da necessidade de priorização política. $O$ ônus financeiro incorrido para a manutenção dessa tropa e seu adestramento no Brasil implicaria, de qualquer modo, em despesas de custeio (Cf. Fontoura, 1999: 228). É fato que a ONU retorna parte dos gastos com pessoal, entretanto, a organização não se responsabiliza pela capacitação e o investimento em equipamentos é, atualmente, bastante limitado. As operações ofensivas implementadas pela FIB implica maiores gastos não somente com equipamento militar, mas também com a necessidade de maior qualificação do pessoal no intuito de reduzir vulnerabilidades e dissuadir os opositores.

Se levarmos em conta a credibilidade brasileira no que tange sua participação em operações de manutenção da paz, principalmente na MINUSTAH, no período entre 2004 e 2006, o reconhecimento do CCOPAB enquanto centro de treinamento, e a atuação positiva de um Chefe militar brasileiro no comando da MONUSCO, pode-se considerar que a contribuição de tropas brasileiras para operações robustas é possível. Entretanto, estes fatores são argumentos que exigem estudo aprofundado, tanto em relação à

\footnotetext{
${ }^{29}$ Disponível em: http://www.iaptc.org. Acesso em 28 de julho de 2014.
} 
capacidade militar brasileira e a real necessidade de equipamentos e de pessoal para estas operações específicas, quanto à intenção positiva da chancelaria em negociar esta contribuição.

\section{Considerações Finais}

É impossivel dizer que a atuação do General-de-divisão Carlos Alberto dos Santos Cruz não tem influenciado a imagem do Brasil, da mesma forma que o desempenho positivo do General-de-divisão José Luiz Jaborandy Júnior da MINUSTAH e do Contraalmirante Flávio Macedo Brasil na UNIFIL. A autorização destes comandos evidenciam o interesse do país em atuar no cenário global e mostrar sua capacidade militar. Enviar tropas para operações ofensivas, entretanto, remete a outras questões, como já referido anteriormente.

No caso da MONUSCO, a operacionalização da proteção de civis expõe os desafios sobre o limite do uso da força nas operações de paz robustas, ao mesmo tempo, em quen apresenta a complexidade sobre a necessidade desta proteção. Consequentemente, novas interpretações sobre o consentimento das partes, a imparcialidade/neutralidade, e o uso da força precisarão ser identificadas. Estudos aprofundados sobre os casos de missões como a MONUSCO, a UNMISS, a MINUSMA e a UNSOM serão necessários para abarcar a amplitude e a complexidade destes conflitos e sua relação com o uso da força, para, assim, designar respostas apropriadas da comunidade internacional.

Ainda que se possa verificar distinta atuação da política externa brasileira no início do século, com envolvimento mais pró-ativo do país nas discussões sobre a implementação das missões de paz e a sua contribuição de tropas, a chancelaria brasileira sublinha que o uso da força não é a solução para o conflito. Se aprovado em 
nome da segurança coletiva, é, inicialmente, a forma que permite que problemas profundos enraizados nas sociedades, manifestados na organização de grupos armados, encontrem, posteriormente, solução política, econômica e social. No caso da RDC, a operacionalização da proteção de civis foi adaptada à sua realidade. O uso legítimo da força implementado pela FIB diversificou o modo como a proteção da violência física é conduzida.

Diante das novas orientações sobre a operacionalização da proteção de civis, fazse indispensáveis estudos que, primeiramente, considerem os aspectos políticos influenciados por este novo conceito na implentação do uso da força na MONUSCO. Claramente, a discussão sobre o envio de tropas militares transpassa distintas dimensões. Ainda que o Brasil tenha provado seu potencial, o questionamento que mais se sobressai para a efetivação de novos engajamentos remete à vontade política, sua prioridade na política externa, alocação de recursos e capacidade militar.

A mídia internacional tem apontado a atuação do General Santos Cruz como decisiva para a estabilização na RDC. Isto angaria à imagem do Brasil maior confiança, entretanto, não é possível afirmar os próximos passos da política externa. Sobretudo, diante do debate já levantado nas Naçõe Unidas e na comunidade internacional, de forma geral, sobre o limite do uso da força. Embora seja evidente o interesse do Brasil em ampliar sua inserção internacional e seu poder de influência no continente africano, a FIB representa um caso inédito na operacionalização da proteção de civis e a chancelaria brasileira, já reconhecida pela cautela e solução pacífica de controvérsias, esmiuçará as problemáticas deste assunto antes que qualquer articulação possa afetar a credibilidade do país. 


\section{Referências Bibliográficas}

Barnett, Michael. Partner in Peace? The UN, regional organizations, and peace-keeping. Review of International Studies: Vol. 21, 1995.pp. 401,433.

Baylis, John; Smith, Steve (Ed.). The Globalization of World Politics: an introduction to international relations. 3nd ed. Oxford: Oxford University Press, 2006. p. 405-424.

Braga, Carlos Chagas Vianna. Revista da Escola de Guerra Naval, Rio de Janeiro, $\mathrm{n}^{\circ} 15$ (2010), p. 11-23. Disponível em: http://www.egn.mar.mil.br/arquivos/revistaEgn/junho2010/Desafios\%20Futuros\%20par a\%20as\%20Opera\%C3\%A7\%C3\%B5es\%20de\%20Paz\%20Brasileiras\%20\%20Carlos\%20Chagas\%20Vianna\%20Braga.pdf.

Blyth, Fiona. Too Risk-Averse, UN Peacekeepers in the DRC Get New Mandate and More Chanllenges. April, 2013. Disponível em: $\mathrm{http}$ //theglobalobservatory.org/analysis/475-too-risk-averse-un-peace-keepers-in-thedre-get-new-mandate-and-more-chanllenges.html.

Donald, Daniel C. F. Partnering for Troop Supply. International Peacekeeping: Vol. 18. N. 5. 2011.

De Souza, Graziene Carneiro. Responsabilidade de Proteger e sua Responsabilidade de Reagir: nova modalidade de intervenção militar? Dissertação de Mestrado. Universidade Federal Fluminense: Niterói. 2012.

Dziedzic, Michael. Perito, Robert M. Haiti: Confronting the Gangs of Port-au-Prince, Special Report 208 United States Institute of Peace, Washington DC, 2008. Disponível em: www.usip.org/resources/haiti-confronting-the-gangs-port-au-prince.

Fett, Priscila. Tudo de novo no front: MONUSCO, uma nova era nas peacekeeping operations? Revista de Direito Internacional, Brasília, V. 10, N. 2. 2013. P. 168-192.

Fontoura, Paulo Roberto Campos Tarrisse de. O Brasil nas Operações de Manutenção da Paz das Nações Unidas. Brasília: FUNAG, 1999. 
Gombata, Marsílea. Missão brasileira no Haiti completa 10 anos em meio a incertezas. Carta Capital. 1.6.2014. Disponível em: http://www.cartacapital.com.br/internacional/minustahcompleta-10-anos-em-meio-a-incertezas-7340.html. Acesso em 22 de julho de 2014.

Malan, Mark. Peacekeeping in the New Millennium: towards "fourth generation" peace operations? African Security Review, v. 7, n. 3, 1998 . Disponível em: http://www.iss.co.za/pubs/asr/7no3/Malan.html.

Rodrigues, Thiago. Segurança Planetária: entre o climático e o humano. Ecopolítica. N.3, 2012. P. 5-41. Disponível em: https://mail.google.com/mail/u/0/\#search/th.rodrigues\%40gmail.com/14b2b68ccbb62a2d ?projector=1.

Uziel, E. O Conselho de Segurança, as Operações de Manutenção da Paz e a inserção do Brasil no Mecanismo de Segurança Coletiva das Nações Unidas. FUNAG, Brasília, 2010.

Vigevani, T.; Cepaluni. A política externa de Lula da Silva: a estratégia da autonomia pela diversificação. Contexto internacional. v.29, n.2, 2007. pp. 273-335.

Weiss, Thomas G. The Sunset of Humanitarian Intervention?T he Responsibility to Protect in a Unipolar Era. Security Dialogue: Vol. 35(2), 2004. pp. 135, 153.

Deutsche Welle. Os desafios de um General brasileiro no Congo. Carta Capital. 4 de mar de 2013. Disponível em: http://www.cartacapital.com.br/internacional/descredito-daonu-e-violencia-rebelde-aguardam-general-brasileiro-no-congo.

Winter, Marcella de Carvalho. A Política Africanista do Governo Lula da Silva (2003 2010) Disponível em: http://www.getempo.org/index.php/revistas/56-n-11-marco-de2013/artigos/161-5-a-politica-africanista-do-governo-lula-da-silva-2003-2010.

(A/47/277- S/24111) “An Agenda for Peace: Preventive diplomacy, peacemaking and peace-keeping". Report of the Secretary-General pursuant adopted by the Summit Meeting of the Security Council on 31 Jan. 1992, 17 Jun. 1992. Disponível em: http://www.un-documents.net/a47-277.htm.

CCOPAB. Disponíel em: http://www.ccopab.eb.mil.br/index.php/pt/ensino/cursos-eestagios. 
Comunicado Conjunto entre a República Federativa do Brasil relativo a visita de Trabalho a República Democrática do Congo. Disponível em: http://www.itamaraty.gov.br/sala-de-imprensa/notas-a-imprensa/comunicado-conjuntoentre-a-republica-democratica-do-congo-e-a-republica-federativa-do-brasil-relativo-avisita-de-trabalho-a-republica-democratica-do-congo-do-ministro-das-relacoesexteriores-do-brasil.

Contribuições das Nações Unidas. MINUSTAH. Disponível em: www.un.org/en/peacekeeping/contributors/2014/jun14_3.pdf.

Contribuições das Nações Unidas. Disponível em: http://www.un.org/en/peacekeeping/operations/global_contribution.shtml.

Estratégia Nacional de Defesa. Ministério da Defesa. Brasil. 2012. Disponível em: http://www.defesa.gov.br/projetosweb/estrategia/arquivos/estrategia_defesa_nacional_ portugues.pdf.

Livro Branco de Defesa. Ministério da Defesa. Brasil. 2012. Disponível em: http://www.defesa.gov.br/arquivos/2012/mes07/lbdn.pdf.

Minustah Completa 10 anos em meio a incertezas. Carta Capital. Disponível em: http://www.cartacapital.com.br/internacional/minustah-completa-10-anos-em-meio-aincertezas-7340.html.

Política Nacional de Defesa. Ministéio da Defesa. Brasil. 2012. Disponível em: http://eblog.eb.mil.br/wp-content/uploads/2013/09/politica_nacional_defesa.pdf.

Pronunciamento do Ministro Antônio de Aguiar Patriota em debate Debate Informal do Conselho de Segurança sobre a Responsabilidade ao Proteger. Disponível em http://www.itamaraty.gov.br/sala-de-imprensa/notas-a-imprensa/pronunciamentodoministrodasrelacoesexterioresantoniodeaguiarpatriotaemdebatesobreresponsabilidad e-ao-proteger-na-onu-2013-nova-york-21-de-fevereiro de2012/?searchterm=Responsabilidade\%20ao\%20Proteger.

Reaparelhamento das Forças Armadas. Disponível em: http://www.senado.gov.br/noticias/Jornal/emdiscussao/defesa-nacional/estrategianacional-para-reorganizaao-e-reaparelhamento-da-defesa/forca-interina-da-onu-nolibano.aspx. 
Relatórios do Secretário-Geral das Nações Unidas sobre a MINUSTAH. Disponível em: http://www.un.org/en/peacekeeping/missions/minustah/reports.shtml.

United Nations Department of Peacekeeping Operations. Handbook on United Nations Multidimensional Peacekeeping Operations. Dez. 2013.

United Nations Department of Peacekeeping Operations. United Nations Peacekeeping Operations: principles and guidelines. 2008.

United Nations Organizations Stabilization Mission in the DRC. MONUSCO Background. Disponível em: http://www.un.org/en/peacekeeping/missions/monusco/background.shtml. Acesso em: 20 de junho de 2014.

United Nations Security Council. Peace, Security and Cooperation Framework for the Democratic Republic of the Congo and the region.UN doc. S/2013/131.5 mar.2013.

United Nations Security Council. Resolution 2098 (S/RES/2098) MONUSCO. 28 mar. 2013.

. Resolution 1265 (S/RES/ 1265) Resolução do Conselho de Segurança. “Wilingness to respond to situations of armed conflict where civilians are being targeted." 17 set. 1999.

.. Resolutin 1296 (S/RES/1296) Resolução do Conselho de Segurança sobre proteção de civis em conflito armado. 19 abr. 2000.

. Peace, Security and Cooperation Framework for the Democratic Republic of the Congo and the region. UN doc. S/2013/131.5 mar.2013.

VII Reunião Ministerial da Zona de Paz e Cooperação do Atlântico Sul (ZOPACAS) Disponível em: http://www.itamaraty.gov.br/sala-de-imprensa/discursos-artigosentrevistas-e-outras-comunicacoes/ministro-estado-relacoes-exteriores/vii-reuniaoministerial-da-zona-de-paz-e-cooperacao-do-atlantico-sul-zopacas-texto-base-dodiscurso-do-ministro-antonio-de-aguiar-patriota-montevideu-15-de-janeiro-de-2013. 